\title{
Crystal and Magnetic Structures of $\mathrm{NaMnF}_{4}$
}

\author{
Michel Molinier and Werner Massa* \\ Fachbereich Chemie und Wiss. Zentrum für Materialwissenschaften der Philipps-Universität, \\ D-W-3550 Marburg \\ S. Khairoun and A. Tressaud \\ Laboratoire de Chimie du Solide du CNRS, Université de Bordeaux I, \\ F-33405 Talence
}

J. L. Soubeyroux

Institut Laue-Langevin, BP 156 X, F-38042 Grenoble

Z. Naturforsch. 46b, 1669-1673 (1991); received May 25, 1991

Fluoromanganate(III), Crystal Structure, Magnetism, Neutron Diffraction, Manganese(III)

An X-ray single crystal structure determination (monoclinic, space group $\mathrm{P} 2 / c, a=$ 573.6(2), $b=489.2(1), c=574.8(2) \mathrm{pm}, \beta=108.07(2), Z=2$; w $R=0.038$ for 380 reflections) shows that $\mathrm{NaMnF}_{4}$ crystallizes in the same layered structure type as $\mathrm{LiMnF}_{4}$. In the quadratic layers the $\mathrm{Mn}-\mathrm{F}-\mathrm{Mn}$ bridges are strongly asymmetric, due to the Jahn-Teller effect, leading to an antiferrodistortive order of elongated octahedra. The bridging angle is 138.4 . The $\mathrm{Na}^{+}$ ions are 6-coordinated as well. The common structural arrangement of both $\left[\mathrm{MnF}_{6}\right]$ and $\left[\mathrm{NaF}_{6}\right]$ octahedra shows topological relation to the rutile structure. In the magnetic measurements performed on powder samples $\mathrm{NaMnF}_{4}$ behaves as an antiferromagnet with a weak ferromagnetic component below $13 \mathrm{~K}$. By neutron diffraction on powder $(4-70 \mathrm{~K})$ a magnetic cell doubled along the $a$-axis is found and below a Neel temperature of $T_{V}=13 \mathrm{~K}$ the magnetic structure shows colinear antiferromagnetic arrangement of the spins pointing slightly (16) out of the layer plane. The resulting magnetic moment is $3.52 \mu_{\mathrm{B}}$.

\section{Introduction}

$\mathrm{AMnF}_{4}$ compounds $\left(\mathrm{A}=\mathrm{K}, \mathrm{Rb}, \mathrm{Cs}, \mathrm{Tl}, \mathrm{NH}_{4}\right)$ have layered structures deriving from the $\mathrm{TlAlF}_{4}$ type as shown by several single crystal X-ray investigations of the $\mathrm{Cs}[1,2]$, Tl [3], and $\mathrm{K}$ [4] compounds, and by powder diffraction work [5]. Owing to the strong Jahn-Teller effect of the $\mathrm{d}^{4}$ high spin configuration of octahedrally coordinated $\mathrm{Mn}^{3+}$, the $\left[\mathrm{MnF}_{6}\right]$ groups show antiferrodistortive ordering of their elongated axes within the quadratic layers. According to the rules for $\sigma$-superexchange, ferromagnetism has been found for $\mathrm{CsMnF}_{4}$ [1]. By magnetic investigations on the Rb, $\mathrm{NH}_{4}$ and $\mathrm{K}$ [6] and the $\mathrm{Tl}$ [3] compounds it has been shown that for smaller cations and, in consequence, for smaller $\mathrm{Mn}-\mathrm{F}-\mathrm{Mn}$ bridge angles, a transition to antiferromagnetic behaviour occurs. Within the scope of investigations on low-dimensional magnets we have been interested in the $\mathrm{AMnF}_{4}$ compound with the next smaller alkali cation and are presenting here the results of an $\mathrm{X}$-ray single crystal structure determination, and

\footnotetext{
* Reprint requests to Prof. Dr. W. Massa.

Verlag der Zeitschrift für Naturforschung, D-7400 Tübingen 0932-0776/91/1200-1669/\$01.00/0
}

of magnetic and neutron diffraction measurements on $\mathrm{NaMnF}_{4}$. For this compound only thermodynamic data had been published until now [7-9].

\section{Experimental}

Single crystals of $\mathrm{NaMnF}_{4}$ were obtained by reaction of $\mathrm{NaF}$ and $\mathrm{MnF}_{3}$ in a sealed platinum tube. The stoichiometric mixture was first heated at $800 \mathrm{C}$ for $45 \mathrm{~h}$, slowly cooled to $650{ }^{\circ} \mathrm{C}$, and then cooled down faster to room temperature. A transparent brown platelet of about $0.175 \times 0.150 \times 0.025 \mathrm{~mm}$ was used for X-ray film exposures on a precession camera and for intensity measurements on a 4-circle diffractometer (CAD4, Enraf-Nonius). The space group was found to be $\mathrm{P} 2_{1} / c$ from the systematic absences $h 0 l: l=2 n+1,0 k 0: k=2 n+1$, with $Z=2$ as in the case of $\mathrm{LiMnF}_{4}$ [10]. The monoclinic lattice constants were refined with 25 high-angle reflections to $a=573.6(2) \mathrm{pm}, b=489.2(1) \mathrm{pm}, c=$ 574.8(2) pm, $\beta=108.07(2)^{\circ}$ giving $\mathrm{d}_{\mathrm{c}}=$ $3.334 \mathrm{~g} \mathrm{~cm}^{-3}$.

The 455 reflections $(\theta: 2-30 ; h:-8-+8 ; k$ : $0-6 ; l: 0-8)$ were collected in $\omega$-scan mode using graphite monochromated MoK $\alpha$-radiation. After elimination of unobserved $\left(\mathrm{F}_{\mathrm{o}}<3 \sigma\right)$ and averaging of symmetry equivalent reflections, $380 \mathrm{~F}_{\mathrm{o}}$ data remained for the refinement of the structure. 
No absorption correction has been applied $(\mu=$ $\left.41.51 \mathrm{~cm}^{-1}\right)$. The calculations were made with the SHELX-76 program system [11]. The structure was refined starting from the atomic parameters of $\mathrm{LiMnF}_{4}[10]$ in the space group $\mathrm{P} 2 / c$ with anisotropic temperature factors to $R=0.0394$ and $\mathrm{w} R=0.0383$ (weights $\mathrm{w}=1 / \sigma^{2}\left(\mathrm{~F}_{\mathrm{o}}\right)$ ) using scattering factors for ions [12]. An anomalous dispersion correction [13] was included and an empirical extinction parameter $\varepsilon=5 \cdot 10^{-7}$ was refined, based on the relation $\mathrm{F}_{\mathrm{c}}(\operatorname{corr})=\mathrm{F}_{\mathrm{c}}\left(1-\varepsilon \mathrm{F}_{\mathrm{c}}{ }^{2} / \sin \theta\right)$. The resulting atomic parameters are compiled in Table I*.

Besides, powder samples of $\mathrm{NaMnF}_{4}$ were prepared for magnetic measurements via the reaction $2 \mathrm{NaF}+\mathrm{Mn}_{2} \mathrm{O}_{3}$, both dissolved in $40 \% \mathrm{HF}$, and let to evaporate. Those measurements have been carried out using both a vibrating sample magnetometer (Foner) and a Faraday microbalance, in a temperature range from 4.2 to $300 \mathrm{~K}$.

Neutron diffraction studies have been performed on the same powder, using the D1B diffractometer at the Institute Laue Langevin in Grenoble. The incident wavelength was $252.4 \mathrm{pm}$. The sample was loaded in a vanadium container and the patterns were recorded in the 6-86 $2 \theta$ range for the 4-70 $\mathrm{K}$ temperature range. The crystallographic and magnetic structures were refined using the Rietveld profile technique with Young's program [14]. The magnetic form factor of the manganese atoms was tabulated from the values of P. J. Brown [15].

* Listings of the structure factors are available from Fachinformationszentrum Karlsruhe, Gesellschaft für wissenschaftlich-technische Information $\mathrm{mbH}$, D-7514 Eggenstein-Leopoldshafen 2, F.R.G., under specification of deposit No. CSD 55851, authors and journal reference.

\section{Results and Discussion of the X-Ray Structure Determination}

$\mathrm{NaMnF}_{4}$ belongs to the wide group of compounds with structures related to the $\mathrm{TlAlF}_{4}$ type. The $\left[\mathrm{MnF}_{6}\right]$ octahedra form quadratic layers parallel to the (100) plane by sharing four corners (Fig. 1). Those $\left[\mathrm{MnF}_{4}\right]$ layers are separated by layers of 6-coordinated $\mathrm{Na}$ cations (Fig. 4). The topology of interconnection of both kinds of octahedral groups corresponds to that of the rutile structure, as was pointed out for the isostructural $\mathrm{LiMnF}_{4}$ [10] and $\mathrm{LiCoF}_{4}$ [17] compounds by Hoppe, Ferey and coworkers.

The $\mathrm{Mn}^{3+}$ Jahn-Teller ion induces a strong elongation of the $\left[\mathrm{MnF}_{6}\right]$ octahedra (long $\mathrm{Mn}-\mathrm{F}$ $216.7(3) \mathrm{pm})$, and it is noticeable that this effect is more pronounced in the present case than in any other compound of the $\mathrm{AMnF}_{4}(\mathrm{~A}=$ alkali metal $)$ series (Tables II, III). The long axes are antiferro-

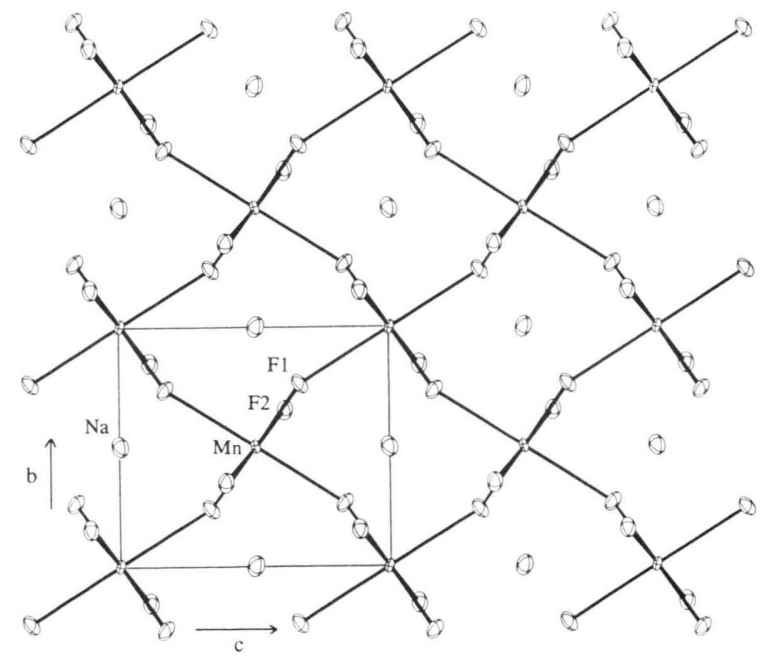

Fig. 1. ORTEP [16] drawing of the $\left[\mathrm{MnF}_{4}\right]$ layer in $\mathrm{NaMnF}_{4}$. Thermal ellipsoids at the $50 \%$ probability level.

Table I. Atomic fractional coordinates and temperature factors $\left[10^{-20} \mathrm{~m}^{2}\right]$ for $\mathrm{NaMnF}_{4}, \mathrm{~T}=\exp \left[-2 \pi^{2}\left(\mathrm{U}_{11} h^{2} a^{* 2}+\ldots\right.\right.$ $\left.\left.+2 \mathrm{U}_{12} h k a^{*} b^{*}\right)\right]$.

\begin{tabular}{lllllllrrr}
\hline Atom & $x$ & $y$ & $z$ & $\mathrm{U}_{11}$ & $\mathrm{U}_{22}$ & $\mathrm{U}_{33}$ & $\mathrm{U}_{23}$ & $\mathrm{U}_{13}$ & $\mathrm{U}_{12}$ \\
\hline $\mathrm{Na}$ & $1 / 2$ & $1 / 2$ & 0 & $0.0193(14)$ & $0.0196(15)$ & $0.0126(12)$ & $-0.0023(16)$ & $-0.0004(10)$ & $0.0063(1$ \\
$\mathrm{Mn}$ & 0 & $1 / 2$ & $1 / 2$ & $0.0120(5)$ & $0.0089(5)$ & $0.0043(4)$ & $-0.0013(5)$ & $0.0026(3)$ & $-0.0005(6$ \\
$\mathrm{F} 1$ & $0.8757(6)$ & $0.7633(6)$ & $0.6655(5)$ & $0.0235(17)$ & $0.0157(15)$ & $0.0123(14)$ & $-0.0055(12)$ & $0.0061(12)$ & $0.0040(1$ \\
$\mathrm{F} 2$ & $0.3014(5)$ & $0.6529(6)$ & $0.6101(5)$ & $0.0168(16)$ & $0.0182(17)$ & $0.0108(13)$ & $0.0007(12)$ & $0.0031(11)$ & $-0.0064(1$ \\
\hline
\end{tabular}


Table II. Characteristic bond lengths (pm) and angles ( ) in $\mathrm{NaMnF}_{4}$.

$\begin{array}{lc}\mathrm{Mn}^{3+} \text { octahedron } \\ \mathrm{Mn}-\mathrm{F} 1^{\text {a.b }} & 2 \times 186.9(3) \\ \mathrm{Mn}-\mathrm{F} 2, \mathrm{~F} 2^{\mathrm{c}} & 2 \times 180.8(3) \\ \mathrm{Mn}-\mathrm{F} 1^{\text {d.e }} & 2 \times 216.7(3) \\ <\mathrm{Mn}-\mathrm{F}> & 194.8\end{array}$

$\mathrm{F} 1^{\mathrm{a}}-\mathrm{Mn}-\mathrm{F} 1^{\mathrm{e}}$ $\mathrm{F} 1^{\mathrm{a}}-\mathrm{Mn}-\mathrm{F} 1^{\mathrm{d}}$ $\mathrm{F} 1^{\mathrm{e}}-\mathrm{Mn}-\mathrm{F} 2^{\mathrm{c}}$ $\mathrm{F} 1^{\mathrm{e}}-\mathrm{Mn}-\mathrm{F} 2$ $\mathrm{F} 1^{\mathrm{b}}-\mathrm{Mn}-\mathrm{F} 2$ $\mathrm{F} 1^{\mathrm{b}}-\mathrm{Mn}-\mathrm{F} 2^{\mathrm{c}}$

$89.4(1)$ $90.6(1)$ $96.0(1)$ $84.0(1)$ $89.4(1)$ $90.6(1)$

$\mathrm{Na}^{+}$octahedron

$\mathrm{Na}-\mathrm{F}^{\mathrm{f}} \mathrm{g}$

$\mathrm{Na}-\mathrm{F} 2^{\mathrm{f} . \mathrm{g}}$

$\mathrm{Na}-\mathrm{F} 2^{\mathrm{b}, \mathrm{h}}$

$<\mathrm{Na}-\mathrm{F}\rangle$
$2 \times 237.0(3)$

$2 \times 224.2(3)$

$2 \times 230.1(3)$

230.4
$\mathrm{F} 1^{\mathrm{f}}-\mathrm{Na}-\mathrm{F} 2^{\mathrm{h}}$

$\mathrm{F} 1^{\mathrm{g}}-\mathrm{Na}-\mathrm{F} 2^{\mathrm{f}}$

$\mathrm{F} 1^{\mathrm{g}}-\mathrm{Na}-\mathrm{F} 2^{\mathrm{h}}$

$\mathrm{F} 1^{\mathrm{g}}-\mathrm{Na}-\mathrm{F} 2^{\mathrm{g}}$

$\mathrm{F} 2^{\mathrm{g}}-\mathrm{Na}-\mathrm{F} 2^{\mathrm{h}}$

$\mathrm{F} 2^{\mathrm{f}}-\mathrm{Na}-\mathrm{F} 2^{\mathrm{h}}$ with a regular increase from $\mathrm{LiMnF}_{4}$ to $\mathrm{CsMnF}_{4}$ (Table III). Considering the puckering type of the layer, i.e. the distribution pattern of the bridging fluorine atoms above and below the manganese plane (Fig. 2), it is interesting to note that according to the alkali cation size, three different arrangements of those fluorine atoms are induced; they are either aligned (in $\mathrm{LiMnF}_{4}$ and $\mathrm{NaMnF}_{4}$ ), in a zigzag pattern (in $\mathrm{KMnF}_{4}$ and $\mathrm{RbMnF}_{4}$ [18]), or building squares (in $\mathrm{CsMnF}_{4}$ ).

The coordination of the $\mathrm{Na}$ ions deviates from a
$110.2(1)$

$90.3(1)$

$69.8(1)$

$89.7(1)$

$96.5(1)$

$83.5(1)$
Metal-metal distance and bridge angle

$\mathrm{Mn}-\mathrm{Mn}^{\mathrm{i}} \quad 377.4(1) \quad \mathrm{Mn}-\mathrm{F} 1^{\mathrm{b}}-\mathrm{Mn}^{\mathrm{i}} \quad$ 138.4(2)

Symmetry codes: ${ }^{\mathrm{a}} x-1, y, z ;{ }^{\mathrm{b}} 1-x, 1-y, 1-z ;{ }^{\mathrm{c}}-x$, $1-y, 1-z ;{ }^{\mathrm{d}} x-1,1.5-y, z-0.5 ;{ }^{\mathrm{e}} 1-x, y-0.5,1.5-z ;{ }^{\mathrm{f}} x$, $1.5-y, z-0.5 ;{ }^{\mathrm{g}} 1-x, y-0.5,0.5-z ;{ }^{\mathrm{h}} x, y, z-1 ;{ }^{\mathrm{i}} x, 0.5-y$, $z-0.5$.

distortively ordered within the layers. Thus, the distances in the two shorter axes are split into very short terminal bonds (180.8(3) pm) and medium short bonds (186.7(3) pm) taking part in the very asymmetric $\mathrm{Mn}-\mathrm{F}-\mathrm{Mn}$ bridges. A survey of the $\mathrm{Mn}-\mathrm{F}-\mathrm{Mn}$ bridging angles, important for the magnetic superexchange interactions, shows that the value found for $\mathrm{NaMnF}_{4}$ is in good agreement regular octahedron not so much regarding the $\mathrm{Na}-\mathrm{F}$ distances ranging from 234 to $237 \mathrm{pm}$, but rather the angles which vary between 69.8 and 110.2 for the "right" $\mathrm{F}-\mathrm{Na}-\mathrm{F}$ angles.

\section{Magnetism}

In the magnetic measurements below $15 \mathrm{~K}$, a remanent magnetization was detected, and the variation of the magnetization $\mathrm{M}$ with $\mathrm{H}$ was roughly of the form:

$$
\mathrm{M}=\mathrm{M}_{0}+\chi \mathrm{H}
$$

The variation of the magnetization extrapolated to zero field $\left(\mathrm{M}_{0}\right)$ with $\mathrm{T}$ (Fig. $3 \mathrm{a}$ ) led to a curve which does not fit well with a Brillouin function, especially in the transition temperature region. Taking the ordering temperature $\mathrm{T}_{\mathrm{N}}=13 \mathrm{~K}$ from the results of neutron diffraction (see below Fig 5), a probable curve for the three dimensional phase may be drawn (solid line). The flat spur above the
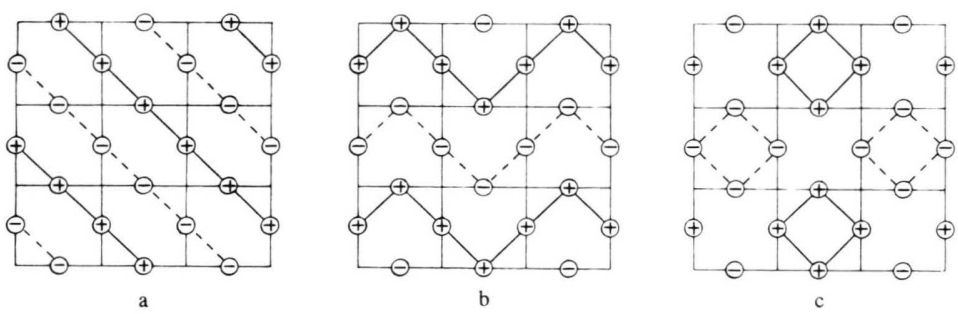

Fig. 2. Scheme of the three different puckering types in the $\mathrm{AMnF}_{4}$ layered structures. $\mathrm{a}: \mathrm{A}=\mathrm{Li}, \mathrm{Na}$; $\mathrm{b}: \mathrm{A}=\mathrm{K}, \mathrm{Rb}$; $\mathrm{c}: \mathrm{A}=\mathrm{Cs}$. The bridging $\mathrm{F}$ atoms are either above $(+)$ or below $(-)$ the plane of the $\mathrm{Mn}$ atoms.

\begin{tabular}{llllll}
\hline Compound & $\begin{array}{l}\text { Mn-F }[\mathrm{pm}] \\
\text { elongated }\end{array}$ & $\begin{array}{l}\text { Mn-F } \\
\text { bridge }\end{array}$ & $\begin{array}{l}\text { terminal } \\
\text { ton }\end{array}$ & Mn-F-Mn [ $\left.{ }^{\circ}\right]$ & Ref. \\
\hline $\mathrm{LiMnF}_{4}$ & 213.7 & 186.9 & 181.8 & 132.7 & {$[10]$} \\
$\mathrm{NaMnF}_{4}$ & 216.7 & 186.9 & 180.8 & 138.4 & this work \\
$\mathrm{TlMnF}_{4}$ & 215 & 186 & 178 & 146.5 & {$[3]$} \\
$\mathrm{RbMnF}_{4}$ & 215.4 & 188.2 & 180.5 & 152.0 & {$[18]$} \\
$\mathrm{CsMnF}_{4}$ & 216.2 & 186.0 & 182.1 & 161.9 & {$[2,18]$} \\
\hline
\end{tabular}

Table III. Comparison of geometric data for $\mathrm{AMnF}_{4}$ compounds. 

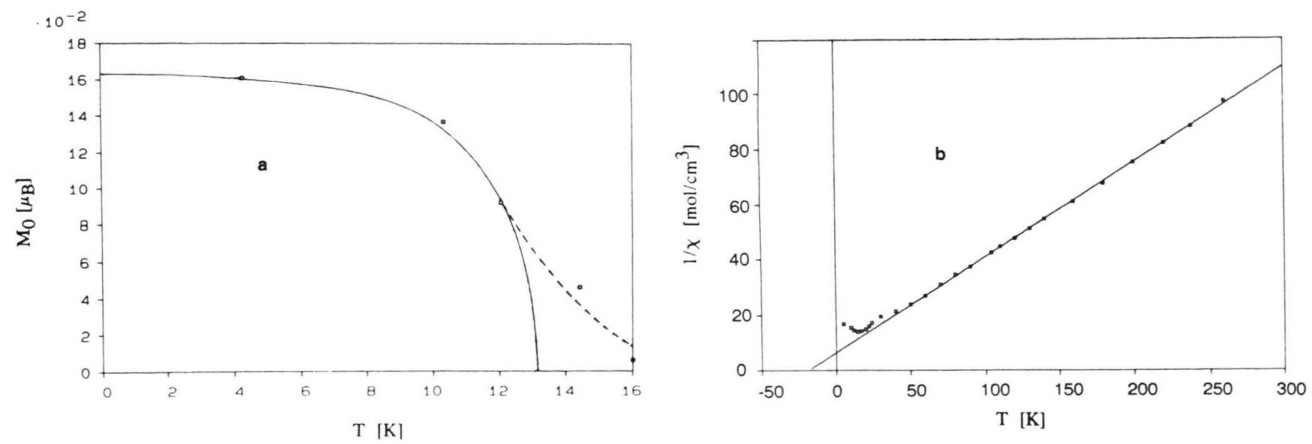

Fig. 3. a: Temperature depencence of zero field magnetization. The lines are guides for the eye (see text); b: Temperature dependence of the reciprocal molar susceptibility of $\mathrm{NaMnF}_{4}$.

ordering point (dotted line) may be attributed to 2-dimensional magnetic phenomena. We are now investigating this interesting regime by means of Mössbauer spectroscopy on Fe doped samples.

The thermal variation of the susceptibility (Fig. 3 b) gave $\theta_{\mathrm{p}}=-19 \mathrm{~K}, \mathrm{C}=2.93$ and $\mu_{\mathrm{eff}}=$

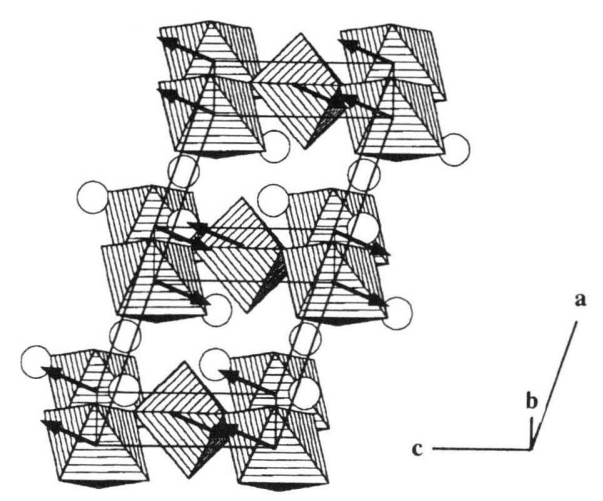

Fig. 4. Magnetic structure of $\mathrm{NaMnF}_{4}$.

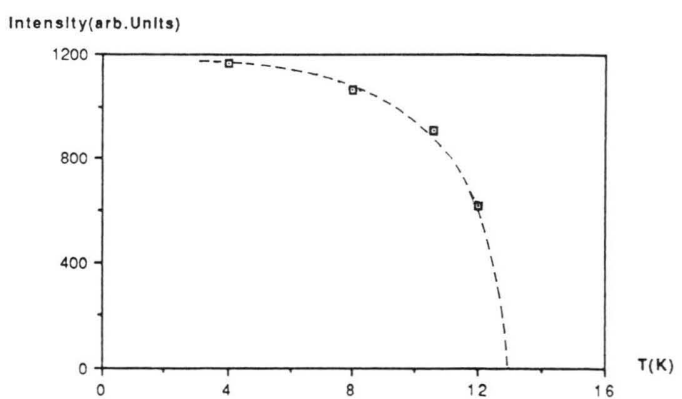

Fig. 5. Variation of the (110) magnetic reflection with temperature.
$4.84 \mu_{\mathrm{B}}$, a value in good agreement with previous results on $\mathrm{Mn}^{3+}$. In that Figure, the values of $\chi$ have been directly taken from the microbalance results for $\mathrm{T}>15 \mathrm{~K}$ and from eq. 1 below $15 \mathrm{~K}$. The $\theta$ value corresponds to that of a bulk antiferromagnet and the origin ordinate value $\mathrm{M}_{0}=0.16 \mu_{\mathrm{B}}$ (Fig. 3a) is consistent with weak ferromagnetism due to slightly canted spins.

\section{Neutron Diffraction}

A neutron diffraction pattern was recorded at $70 \mathrm{~K}$ in the paramagnetic region. The refinement confirmed the structure found by X-ray single crystal analysis with slightly different parameters due to the temperature dependence (Table IV).

Several patterns have been recorded in the range 4-20 $\mathrm{K}$ in order to estimate the ordering temperature. The extrapolation of the intensity of the (110) reflection as shown in Fig. 5 leads to $\mathrm{T}_{\mathrm{N}}=$ $13 \pm 0.5 \mathrm{~K}$. In the $4 \mathrm{~K}$ pattern, additional reflections were observed and indexed with a propaga-

\begin{tabular}{lrr}
\hline & \multicolumn{1}{c}{$70 \mathrm{~K}$} & \multicolumn{1}{c}{$4 \mathrm{~K}$} \\
\hline$a(\AA)$ & $5.755(2)$ & $5.755(1)$ \\
$b(\AA)$ & $4.892(1)$ & $4.889(1)$ \\
$c(\AA)$ & $5.760(2)$ & $5.755(1)$ \\
$\beta()$ & $108.62(1)$ & $108.67(1)$ \\
$x \mathrm{~F} 1$ & $0.878(1)$ & \\
$y \mathrm{~F} 1$ & $0.767(1)$ & \\
$z \mathrm{~F} 1$ & $0.660(1)$ & \\
$x \mathrm{~F} 2$ & $0.304(1)$ & \\
$y \mathrm{~F} 2$ & $0.651(1)$ & \\
$z \mathrm{~F} 2$ & $0.615(1)$ & \\
\hline
\end{tabular}

Table IV. Lattice parameters and fractional coordinates from the neutron diffraction data on $\mathrm{NaMnF}_{4}$. 
Table V. Observed and calculated intensities of magnetic reflections for $\mathrm{NaMnF}_{4}$ at $\mathrm{T}=4 \mathrm{~K}(\mathrm{~m}=$ multiplicity).

\begin{tabular}{rlllrr}
\hline$h$ & $k$ & $l$ & $\mathrm{~m}$ & $\mathrm{I}_{\text {obs. }}$ & $\mathrm{I}_{\text {calc. }}$ \\
\hline 1 & 0 & 0 & 2 & 183 & 177 \\
-1 & 0 & 1 & 2 & 457 & 486 \\
1 & 1 & 0 & 4 & 3648 & 3575 \\
1 & 0 & 1 & 2 & 507 & 368 \\
-1 & 1 & 1 & 4 & 4 & 11 \\
3 & 0 & 0 & 2 & 18 & 15 \\
-3 & 0 & 1 & 2 & 844 & 661 \\
1 & 1 & 1 & 4 & 8 & 13 \\
3 & 1 & 0 & 4 & 1093 & 1142 \\
-3 & 1 & 1 & 4 & 14 & 8 \\
-1 & 0 & 2 & 2 & 37 & 7 \\
3 & 0 & 1 & 2 & 188 & 299 \\
-3 & 0 & 2 & 2 & 4 & 5 \\
-1 & 1 & 2 & 4 & 221 & 177 \\
1 & 0 & 2 & 2 & 7 & 6 \\
3 & 1 & 1 & 4 & 8 & 7 \\
-3 & 1 & 2 & 4 & 286 & 250 \\
-5 & 0 & 1 & 2 & 303 & 237 \\
-1 & 2 & 1 & 4 & 526 & 421 \\
3 & 2 & 0 & 4 & 27 & 2 \\
5 & 1 & 0 & 4 & 333 & 334 \\
\hline
\end{tabular}

tion vector $\mathrm{Q}=(1 / 2,0,0)$. Choosing the magnetic atoms in the magnetic cell as follows:

$$
\begin{aligned}
& \text { Mn 1: } 0,0,0 \\
& \text { Mn 2: } 0,1 / 2,1 / 2 \\
& \text { Mn 3: } 1 / 2,0,0 \\
& \text { Mn 4: } 1 / 2,1 / 2,1 / 2
\end{aligned}
$$

the magnetic intensities are in good agreement with those calculated (Table V) assuming a colinear arrangement of the moments with:

along $x, \mathrm{Ax}=\mathrm{M} 1 x-\mathrm{M} 2 x-\mathrm{M} 3 x+\mathrm{M} 4 x$ with a moment value $\mathrm{M} x=(1.0 \pm 1) \mu_{\mathrm{B}}$

along $y, \mathrm{Cy}=\mathrm{M} 1 y+\mathrm{M} 2 y-\mathrm{M} 3 y-\mathrm{M} 4 y$ with a moment value $\mathrm{M} y=(0.4 \pm 1) \mu_{\mathrm{B}}$

along $z, \mathrm{Az}=\mathrm{M} 1 z-\mathrm{M} 2 z-\mathrm{M} 3 z+\mathrm{M} 4 z$ with a moment value $\mathrm{M} z=(3.70 \pm 5) \mu_{\mathrm{B}}$

The reliability factor $R$ is about $10 \%$. The magnetic structure is shown in Fig. 4. The resultant magnetic moment $\mathrm{M}=3.52 \pm 5 \mu_{\mathrm{B}}$ is close to the expected value for a $\mathrm{S}=2$ magnetic ion. The quality of the pattern did not allow either to determine or to exclude the small canting of spins suggested by the magnetization measurements. It is worthwhile to note that this magnetic structure differs from that of antiferromagnetic $\mathrm{TlMnF}_{4}$ [3] not only by the offset of the spin direction out of the $\left[\mathrm{MnF}_{4}\right]$ layer, but mainly in the inter-layer coupling mode which is antiferromagnetic here, whereas it is ferromagnetic in the case of the $\mathrm{Tl}$ compound. In $\mathrm{CsMnF}_{4}$ [1] both intra- and interlayer couplings are ferromagnetic.

W. M. and M. M. thank the Commission of the European Communities for financial support (grant $\mathrm{N}^{\circ} \mathrm{B} / 89000863$ ). This work has been also supported by the Deutsche Forschungsgemeinschaft and the Fonds der Chemischen Industrie.
[1] W. Massa and M. Steiner, J. Solid State Chem. 32, 137 (1980).

[2] W. Massa, Gesellschaft Deutscher Chemiker, Hauptversammlung, Bonn 1989, VCH Weinheim, p. 323.

[3] P. Nuñez, A. Tressaud, J. Grannec, P. Hagenmuller, W. Massa, D. Babel, A. Boireau, and J. L. Soubeyroux, Z. Anorg. Allg. Chem., in press.

[4] W. Massa, Habilitationsschrift, Marburg (1982).

[5] W. Massa, Inorg. Nucl. Chem. Lett. 13, 253 (1977).

[6] P. Köhler, W. Massa, D. Reinen, B. Hofmann, and R. Hoppe, Z. Anorg. Allg. Chem. 446, 131 (1978).

[7] E. B. Rudnyi and A. Ya. Borshchevskii, Deposited Doc., VINITI 1809 (1981).

[8] V. D. Gubarevich, Deposited Doc., VINITI 3167, 104 (1981).

[9] L. N. Sidorov and V. D. Gubarevich, Koord. Khim. 8, 463 (1982).

[10] K. H. Wandner and R. Hoppe, Z. Anorg. Allg. Chem. 546, 113 (1987).
[11] G. M. Sheldrick, SHELX-76, Program for Crystal Structure Determination, Cambridge University, Cambridge, England (1976).

[12] D. T. Cromer and J. D. Mann, Acta Crystallogr., Sect. A 24, 321 (1968).

[13] D. T. Cromer and D. Liberman, J. Chem. Phys. 53, 1891 (1970).

[14] R. A. Young and D. B. Wiles, J. Applied Cryst. 14, 149 (1981).

[15] P. J. Brown, to be published in International Tables for Crystallography, Vol. C.

[16] C. K. Johnson, ORTEP, A Fortran Thermal Ellipsoid Plot Program for Crystal Structure Illustrations, Report ORNL-3794, Oak Ridge, Tennessee (1965).

[17] P. Lacorre, J. Pannetier, F. Averdunk, R. Hoppe, and G. Ferey, J. Solid State Chem. 79, 1 (1989).

[18] M. Molinier and W. Massa, submitted to Z. Naturforsch. 